\title{
Synthesis of Carbon Nanofibers by a Glow-arc Discharge
}

\author{
Marquidia Pacheco, Joel Pacheco and Ricardo Valdivia \\ Instituto Nacional de Investigaciones Nucleares, \\ Mexico
}

\section{Introduction}

The carbon nanofibers (CNF) consist of graphite platelets arranged in diverse orientations with respect to the fiber axis and present distinctive and special functional properties; these structures have a large number of edges and remarked chemical interaction that favor the absorption capacity [1], they also have a high-catalytic activity which can be used as solid carbon supports for other catalytic reactions [2], [3].

Because all these remarkable features, CNF are quite appropriate for health $[4,5]$ and atmospheric pollutants treatment [6-8], on-chip interconnect integration $[9,10]$ and they can also be used like chemical or biochemical sensing on molecular scale [11] .

To appreciate, a little bit more, the vast world of carbon nanostructures, M.Monthioux and V. Kuznetsov describe, from a carefully point of view [12], some amazing data about the history of carbon nanostructures; in particular they mention a patent of Thomas Alba Edison in 1892, dealing on the synthesis of carbon filaments for an incandescent lamp, employing a thermal decomposition of gaseous methane. However, such patent can not be considered as the first evidence for the growth of carbon nanotubes nor nanofibers, since the resolution of the available optical microscopes were scarcely able to image filaments smaller than few micrometers in diameter. Thanks to the subsequent invention of the transmission electron microscope (TEM), in 1953 first TEM images of CNF were published [13].

At the end of the fifties and during the sixties, many laboratories and companies begin to be interested on CNF, for example, R. Bacon had synthesized CNF of about 200nm by the electric arc technique [14]. Later, during the 70's, A. Oberlin, M. Endo and co-workers have obtained CNF of about 7nm with the chemical vapour deposition (CVD) technique [15-17].

Afterward, new techniques of CNF synthesis were constantly reported in literature. Nowadays, they exist a large quantity of methods to synthesize carbon nanofibers, the most common is the CVD method; this gas-phase process, generally, operate at lower temperatures, the experiment is carried out in a flow furnace at atmospheric pressure. In perhaps the simplest experimental setup, the catalyst is placed in a ceramic boat which is then put into a quartz tube. A reaction mixture consisting of, for example, acetylene and argon is passed over the catalyst bed for several hours at temperatures ranging from 500 to $1100^{\circ} \mathrm{C}[18-23]$.

Another technique to vapour-grown CNF production is based on a 'floating catalyst' carried in the gas stream inside a continuous flow reactor [24]. Supported catalysts have been used 
for CNF synthesis to achieve control of fiber width. Silica-supported Fe, Ni or Co catalysts produce narrow tubular $\mathrm{CNFs}$ from $\mathrm{CO} / \mathrm{H}_{2}$ and ethylene $/ \mathrm{H}_{2}$ mixtures [25]. A similar technique but on water-soluble supports $\left(\mathrm{Na}_{4} \mathrm{SiO}_{4}, \mathrm{Na}_{2} \mathrm{SiO}_{3}\right.$, and $\left.\mathrm{Na}_{2} \mathrm{CO}_{3}\right)$ is also used [26]. A relative new technique to synthesize $\mathrm{CNF}$, is based on an electrospinning process, were a polymer solution is delivered from syringe to a collector with two electrodes with several shapes $[27,28]$.

Concerning plasma processes for carbon nanostructures synthesis, the electric arc technique has been used to synthesize mostly carbon nanotubes [13, 29,30] but also CNF [31-33].

The CVD traditional technique is now enhanced with plasma technology; it has two advantages compared with the conventional CVD method: low process temperature and more flexible film properties [34-38].

A plasma technique that is also used for carbon nanostructures synthesis is the plasma torch; however a relatively low yield of these structures is produced [39]. Its principal limitation could be the very short residence time (lower than 1ms) of catalyst particles in the plasma because of high axial velocity of plasma jets (axial velocity can attain $300 \mathrm{~m} / \mathrm{s}$ ).

The work herein presented is dedicated to the investigation of CNF synthesis using combination energy for two types of plasma (glow discharge and electric arc discharge) in order to diminish energy consumption. Our aim is then, to propose an alternative to the existing plasma methods for CNFs synthesis. Here, we propose an approach consisting in a high frequency glow-arc discharge working under low power consumption $(<300 \mathrm{~W})$ and low flow rates of hydrocarbon injection $(<0.1 \mathrm{lpm})$. This method has additional advantages such as very short reaction times, simple to operate (it requires neither substrates nor special pretreatments) and low cost arrangement (expensive vacuum equipment is not involved).

\section{Principle.}

The present work deals with the growth of CNF by a glow-arc HF discharge; the alternating electric field across the electrodes and the temperature in the gap, provide the energy and dynamics necessary for the dissociation of carbon coming from an hydrocarbon gas $\left(\mathrm{CH}_{4}+\right.$ $\mathrm{He}$ ) and from graphite electrodes to form $\mathrm{CNF}$ assisted by the transition metal catalysts $(\mathrm{Ni}$, Y).

Although the conversion of the carbon and the catalyst to carbon nanostructures by arc discharge and laser method is very efficient, the energy consumption to vaporize the carbon becomes their principal drawback. To atomize a mol of graphite a quantity of $716.6 \mathrm{~kJ}$ of energy is needed compared with $80 \mathrm{~kJ} / \mathrm{mol}$ if methane gas is used into the plasma discharge. Consequently, we propose an alternating process, by using not a high power DC discharge, but a high frequency and low power discharge assisted by methane as carbon-containing gas.

The method here exposed is characterized to have two discharge regimes: a glow discharge and an electric arc discharge. Glow discharge is characterized to have very energetic electrons contrary to other species in plasma with lower kinetic energies, a very characteristically mauve light, under our conditions, is emitted at, approximately, ambient temperature. This discharge is used to pre-heat catalysts to react with the carbon containing gas (CH4) when the electric arc is established. Under this electric arc regime, the sublimation of carbon occurs and the subsequent reaction with the catalyst takes place. The electric arc regime is characterized to be close to local thermodynamical equilibrium, it means that electrons and heavy particles have almost the same kinetic energy or temperature, which easily can reach $4000 \mathrm{~K}$ up to $12000 \mathrm{~K}$. 
The advantage to employ an alternating current (AC) and HF discharge is to obtain quasi instantaneous breakdown voltage peaks, getting enough specific energy to dissociate and to ionize the carbon supply, and consequently, the CNF synthesis is obtained at lower energy consumption.

During the processes, a particle agglomeration takes place in the inter-electrode gap; this effect has been observed by some authors [40-42]. They have found that the particles flowing through the gap depend on the alternating electric field intensity, gravitational force and friction forces described by the Newton motion equation. The amplitude of oscillation decreases with increasing frequency in the electric field vector. Higher frequencies are then, more appropriate because lower amplitude of particles oscillation results in lower probability of their precipitation to the electrodes, and therefore small power consumption is needed to attain the carbon sublimation.

To characterize some physical parameters during the plasma processes, a spectroscopic technique is applied: the optical emission spectroscopy (OES), which examines the wavelengths of photons emitted by the plasma species, during their transition from an excited state to a lower energy state. Each element emits a characteristic set of impulsions at specific wavelengths according to its electronic structure; by observing these wavelengths the elemental composition of the sample can be determined; furthermore, additional parameters like electronic and rotational temperatures (molecules temperature) and electron density, for example, can be obtained. This technique has the enormous advantage to be a non intrusive method.

\section{Experimental set-up.}

The plasma discharge was generated inside a reactor where the pressure could be controlled by a very simple pumping system, within a $10-100 \mathrm{kPa}$ range. The electric energy is provided by a high frequency resonant converter specially designed for this purpose (see figure 1(a)) [43]. The AC current can be adjusted from $10 \mathrm{~mA}$ up to $2 \mathrm{~A}$ peak to peak. The frequency of the applied voltage will affect the voltage at which breakdown occurs, in stable condition the breakdown voltage is $200 \mathrm{~V}$. In general, if DC voltage is used, a higher breakdown voltage will be required [44]. The curves of the electric evolution from glowtoarc discharge as well as the traces of voltage versus current in both regimes were plotted using the real data obtained during the experiments carried out with the setup described in figure 1(a). These results are shown in figure 1(b) [45]. By multiplying the voltage by the current, the instant power applied to the plasma is determined and the rms power values are $51 \mathrm{~W}$ for glow discharge and $96.7 \mathrm{~W}$ for the arc discharge. In the electric diagnostic, it is clear that the arc-regime discharge consumes more power than the glow-regime discharge. The difference, however, is small; in fact, the arc regime requires $45.7 \mathrm{~W}$ more than the glow regime because the arc discharge exists almost $100 \%$ of the time, and the glow regime presents discontinuities. The reason is that some hydrogen atoms are free when the $\mathrm{CH}_{4}$ molecule bonds are broken, and it causes an increment of the electric conductivity of the plasma requiring, then, less power to sustain the arc regime. The temperature dependence of the electric conductivity of various gases $\left(\mathrm{H}_{2}, \mathrm{He}, \mathrm{N}_{2}\right.$ and $\left.\mathrm{Ar}\right)$ shows that $\mathrm{H}_{2}$ presents more conductivity than $\mathrm{He}$; this is due to the higher ionization potential of $\mathrm{He}$ [46].

The plasma reactor has a special optical port for measurement. The optical signal of the plasma discharge was guided by an optical fiber mounted in a XY electromechanical system to achieve a vertical and horizontal scanning of the plasma discharge with very precise 
incremental steps $(0.1 \mathrm{~mm})$. The final end of the optical fiber is focused into the entrance slit of the monochromator, equipped with an 1800 grooves/ $\mathrm{mm}$ holographic grating.

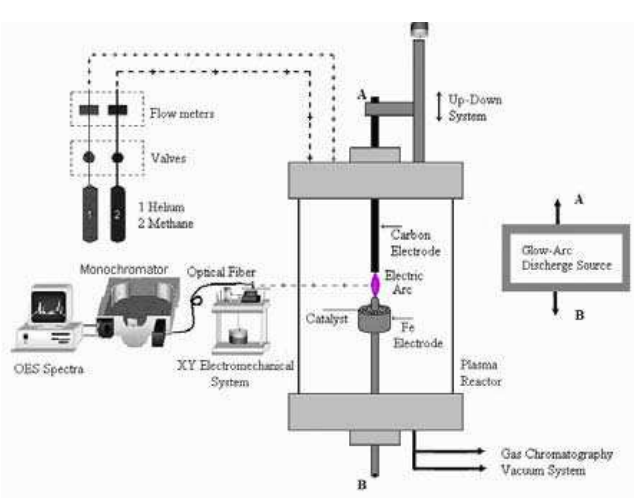

(a)

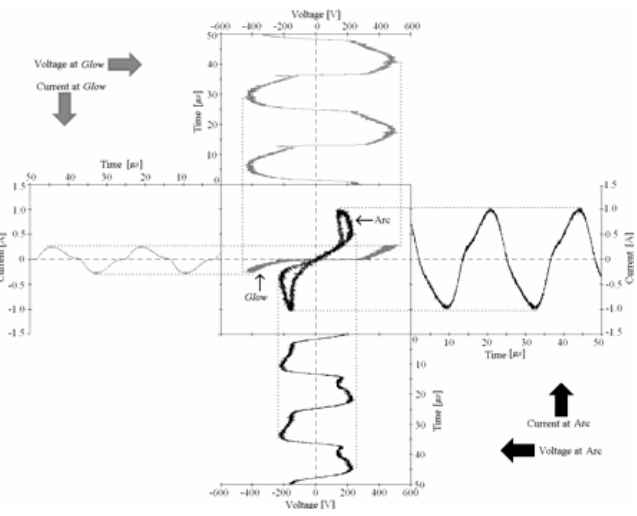

(b)

Fig. 1. (a) Experimental set-up for CNF synthesis, (b) Electric waveforms during glow-arc process [45]

The inferior electrode plays at the same time the role of powder catalyst container. The catalysts mixture (34\%at.Ni/10.32\%at.Y/55.68\%at.C) is disposed in the lower electrode (see figure 2). Two configurations of the lower electrode (containing the catalysts) were tested; in figure 2 a perforated structure with $1 \mathrm{~mm}$ diameter holes is showed and a simplest configuration electrode consisting in a cylindrical carbon electrode with a co-axial hole drilled at its centre, filled with graphite powder and catalyst.

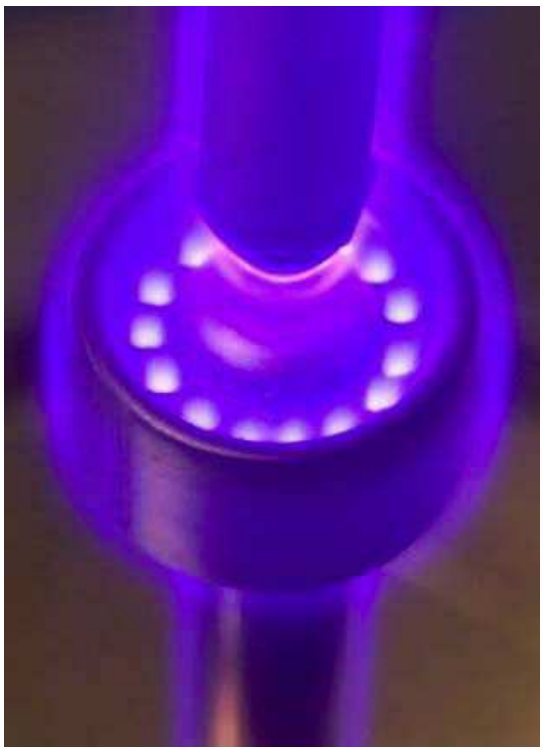

Fig. 2. Glow discharge and detailed view of the lower electrode. 
The upper pure carbon electrode $(10 \mathrm{~mm}$ diameter, $100 \mathrm{~mm}$ long) can be automatically adjusted to conserve a constant gap of $5 \mathrm{~mm}$. All the operating conditions were performed under stable conditions at $42 \mathrm{kHz}$ of frequency and the power source was varied from 150 to 400 watts. Methane was used as carbon containing gas at a feed rate of $0.1 \mathrm{l} / \mathrm{min}$. Helium flowing at $0.31 / \mathrm{min}$ was used as a plasma gas.

A great advantage of using an alternating electric field is that a fine control of two separated regimes (glow and arc discharge) can be accomplished. Figure 2 shows a glow discharge required for the catalyst heating during a previous time (just a few seconds) to produce some vapours used to react with the carbon containing gas $\left(\mathrm{CH}_{4}\right)$ when the electric arc is established (figure 3). Under this regime, the sublimation of carbon occurs and the subsequent reaction with the catalyst takes place.

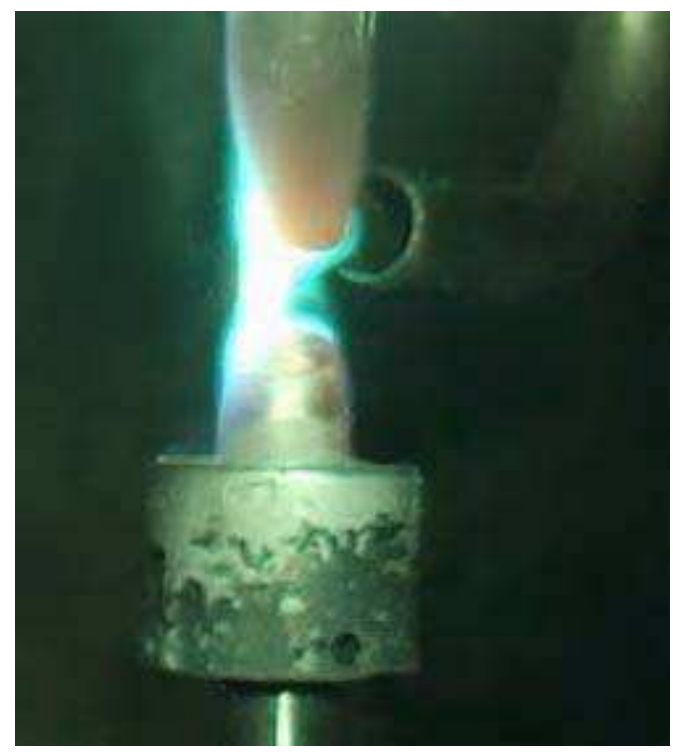

Fig. 3. Electric arc discharge

\section{Results and discussion}

\subsection{Optical emission spectroscopy diagnostic}

OES is one of the most used techniques for plasma diagnosis. The optical emission measurements of the Swan Band are commonly used in the diagnosis of high or even in low temperature processes by introducing carbon materials in the process.

For plasmas in departure from local thermal equilibrium, the rotational, vibrational and excitation temperatures from electrons can differ from those of the heavy species temperatures. Taking into account the relation between the rotational and translational states, the rotational temperature is derived generally from the temperature of heavy particles. Then, the temperature of heavy particles can be obtained from the measurement of the rotational temperature using the $C_{2}(0,0)$ Swan band situated between $513 \mathrm{~nm}$ and $517 \mathrm{~nm}$. The evolution of the optical spectrum of the plasma in the Swan band for both atmospheres $\left(\mathrm{He}\right.$ and $\left.\mathrm{He}+\mathrm{CH}_{4}\right)$, is presented in figure 12. It is clear from this figure, that the methane gas 
accelerates the glow-to-arc discharge process; the transition evolution is reduced five times. In addition, the spectrum intensity under $\mathrm{He}-\mathrm{CH}_{4}$ atmosphere is higher than under $\mathrm{He}$ atmosphere. Applying the method described elsewhere [47, 48], temperature values of $6180 \mathrm{~K}$ and $4830 \mathrm{~K}$ are obtained under $\mathrm{He}$ and $\mathrm{He}-\mathrm{CH}_{4}$ atmospheres, respectively.

These are sufficient high temperatures to accomplish the catalyst, the carbon and the methane sublimation. Unfortunately, the diagnostic can not be prolonged until the final of the experiments, because dusty plasma rapidly fills out the reactor, and consequently, the spectral lines could not be clearly distinguished from the background, leading to a relatively large uncertainty under these conditions.

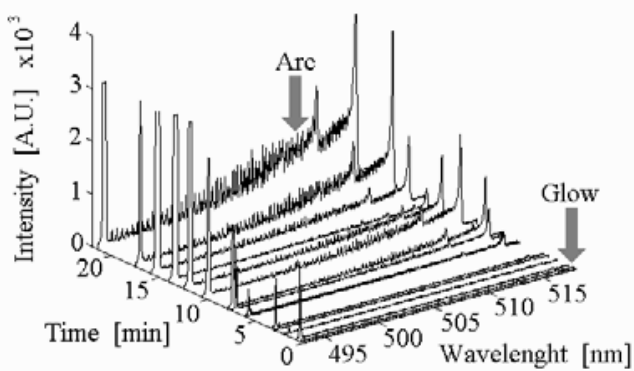

(a)

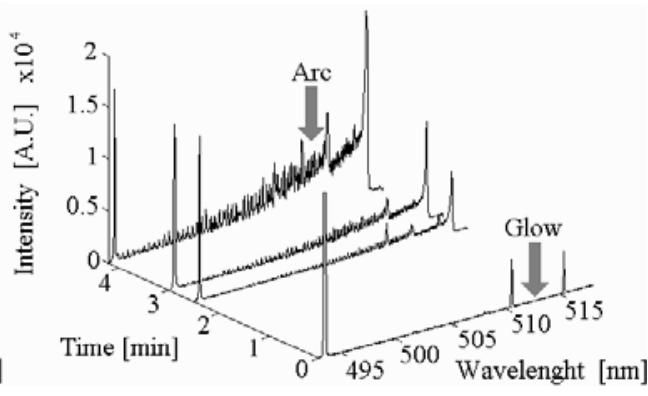

(b)

Fig. 4. OES evolution from glow-to-arc under atmosphere of: (a) $\mathrm{He}$, (b) $\mathrm{He}-\mathrm{CH}_{4}$

\subsection{Morphological analysis}

It is worth to note that the main product accumulation is formed in both electrodes because of the alternative current (figure 5), having, a major percentage of this product accumulated in the upper electrode due to the convection effect. In a dc electric arc discharge, usually employed to generate carbon nanotubes, only the cathode accumulates the carbon product in a more compact way (figure 6) [29].

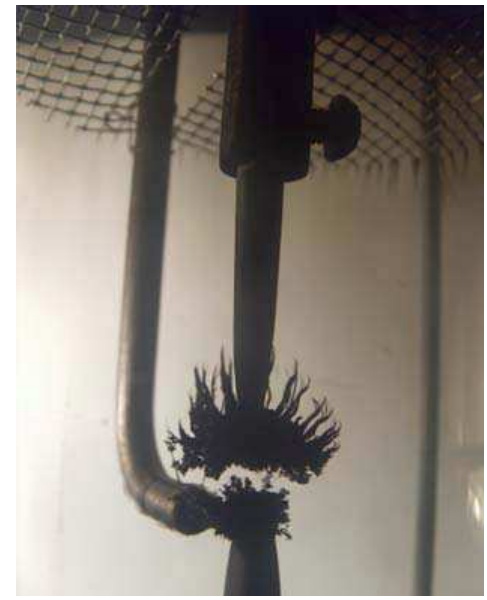

Fig. 5. Carbonaceous depot in both electrodes when ac current is used 


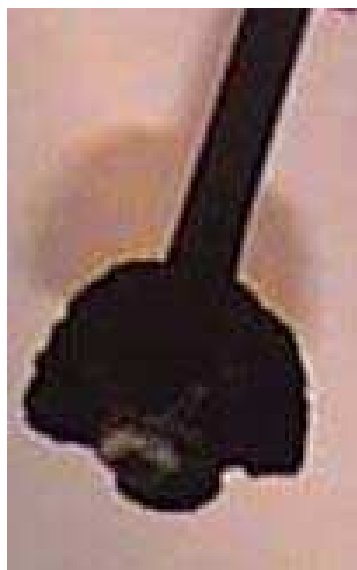

Fig. 6. Carbonaceous depot in cathode, when dc current is used

The main product was collected from the electrodes and the soot-like deposits from the reactor wall, then it was subjected to ultrasonic treatment in iso-propilic alcohol for 10 minutes and finally it was analyzed by a JEOL JSM-5900LV scan electronic microscopy. Samples studied are mostly composed by carbon nanofibers (figure 7). An additional purification experiment with toluene solution during 5 min leads in a final product quite free of amorphous carbon, as can be shown in figure 8. Very similar morphological structure was obtained by Matsuura and co-workers [49], in a plasma reactor with twelve-phase alternating current discharge and $3 \mathrm{~kW}$ of power.

To further characterize the CNF microstructure, an analysis was done with JEOL 2010 Transmission Electron Microscope. Images of the samples are displayed in figure 9 and 10, where homogeneous nanofibers were observed; the CNF diameters vary from $30 \mathrm{~nm}$ to 200nm. Figure 9 shows a CNF with diameter of about 120nm. Figure 10 shows a thicker CNF with relatively periodic joints, as those observed by [50], with $30 \mathrm{~nm}$ of external diameter and an inner diameter of about $15 \mathrm{~nm}$.

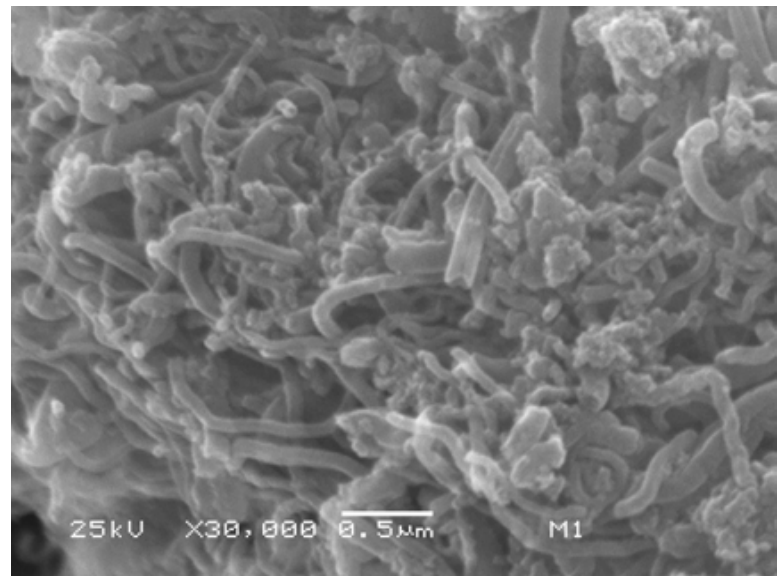

Fig. 7. SEM image detailing classical "spaghetti" morphology. 


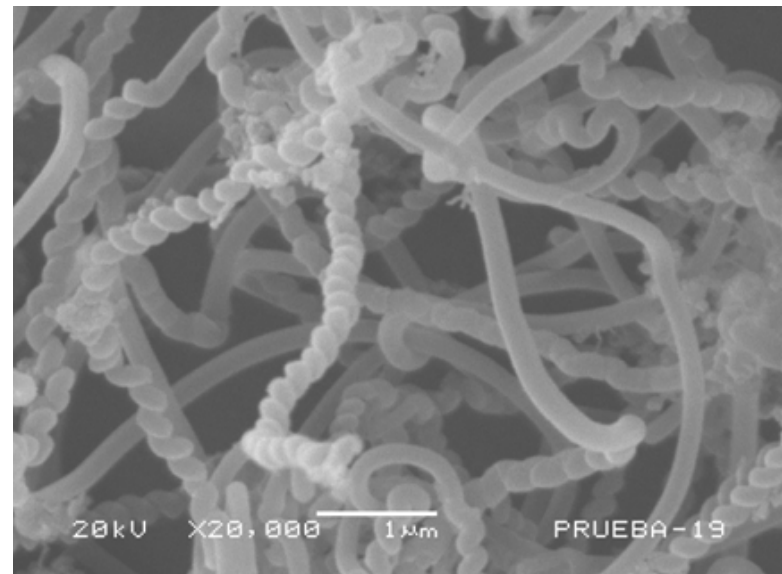

Fig. 8. SEM image detailing some braided nanofibers (purified sample).

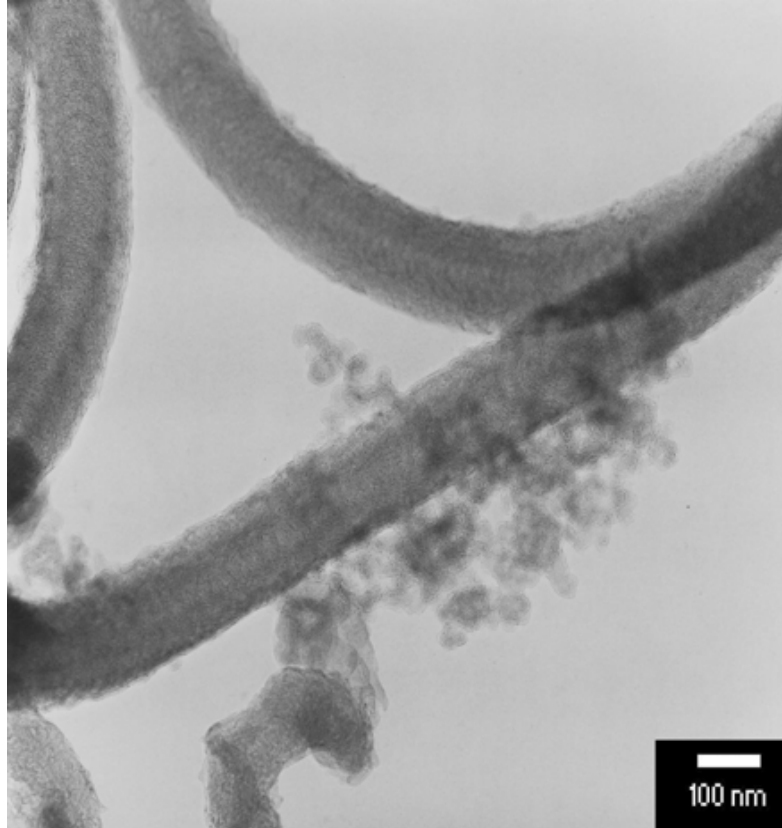

Fig. 9. CNF with relatively high diameter

\subsection{XRD results.}

In figure 11, four X-ray diffraction patterns are superposed. Relatively high CNFs quantity is corroborated with these patterns. Each pattern corresponds to samples obtained under very specific operational conditions. Sample a) is the catalyst-graphite mixture before their exposure to the plasma; this X-ray pattern shows a rich crystalline structure. Sample b) was obtained at low applied power $(158 \mathrm{~W})$. After the electronic microscopy study (SEM and 


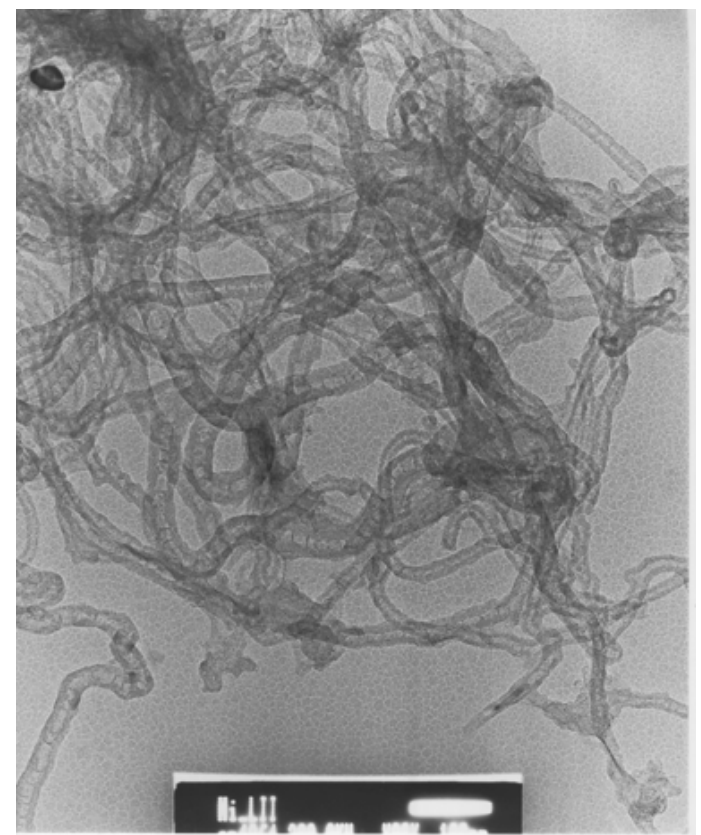

Fig. 10. CNF with periodic joints

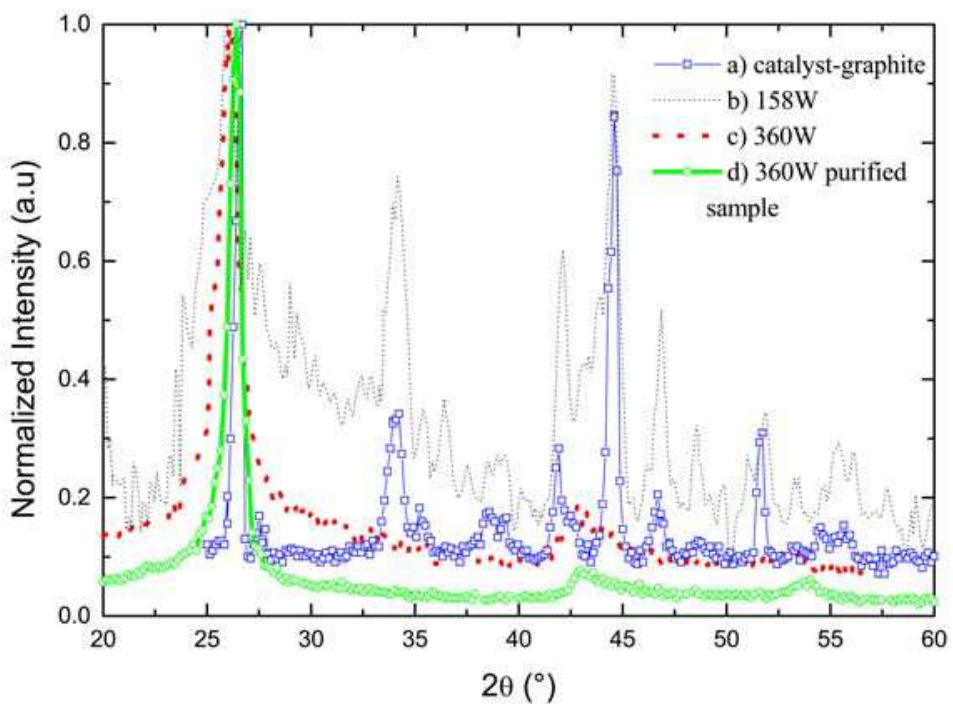

Fig. 11. X-ray diffraction patterns

TEM) it was found that the CNFs were not representative, however the X-ray pattern still shows a polycrystalline structure. The sample c) was obtained under $360 \mathrm{~W}$ of applied power. The X-ray spectrum exhibits few defined peaks indicating a reduced crystalline structure of CNFs [51]. The most intense peaks are $\left(\begin{array}{lll}0 & 0 & 2\end{array}\right)$ and $\left(\begin{array}{lll}1 & 0 & 0\end{array}\right)$ peaks respectively 
situated at $26.25^{\circ}$ and $42.20^{\circ}$ in a $2 \theta$ system. The $26.25^{\circ}$ angle corresponds to the interplanar spacing $\mathrm{d}_{002}$ of carbon nanofibers and nanotubes [52]. Finally, spectrum $\mathrm{d}$ ) corresponds to a purified sample. Peak $\left(\begin{array}{lll}0 & 0\end{array}\right)$ is more intense than peaks found in other samples.

\subsection{Raman scattering results}

To support our analysis obtained by SEM, TEM and XRD techniques a fourth one was applied. The samples were also analyzed by the Raman scattering technique which is mostly used to characterize the crystalline structure.

The main criterion used in literature $[50,53]$ to reveal the carbon nanostructures quality by Raman scattering technique, is the ratio between the peaks $G$ to $D$. The $G$ peak is located around $1590 \mathrm{~cm}^{-1}$ and attributes C-C elongated vibration of graphite layers, indicating a well graphitized carbon nanostructure. Imperfect graphite structure is characterized by the D peak, near $1349 \mathrm{~cm}^{-1}$, and it is also associated with the existence of amorphous carbon fragments rather than structure imperfections. The peak B situated at $159 \mathrm{~cm}^{-1}$ usually represents the radial breathing mode (RBM) in monowall carbon nanotubes. The formation of nanofibers instead of nanotubes could be explained by the presence of hydrogen in the plasma discharge that will terminate the dandling bonds at the edges of stacked graphite platelets [54].

From figure 12 it is deduced that the G/D ratio is around 1.41 corresponding to a high quality of samples [55 - 57].

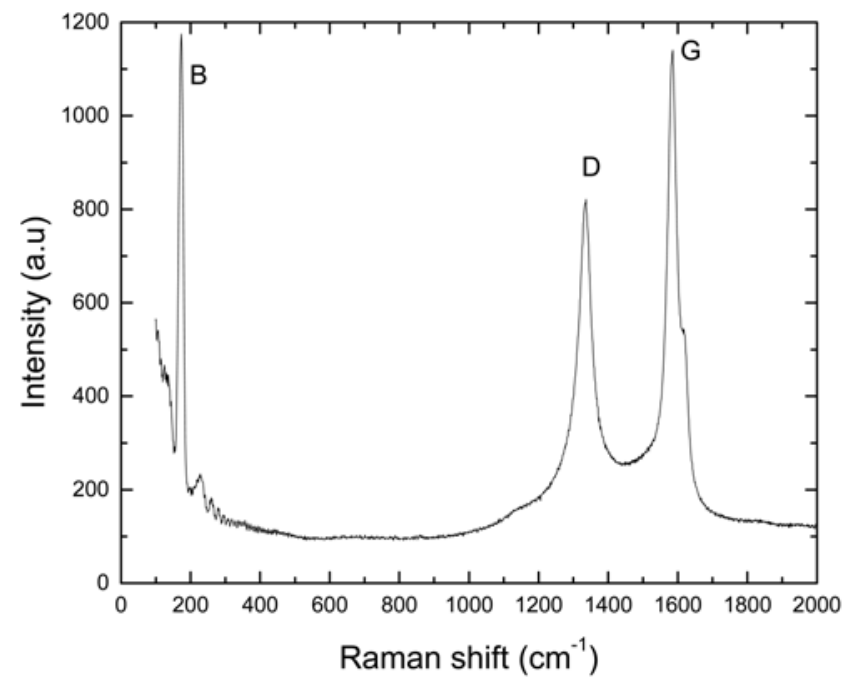

Fig. 12. Raman spectrum for sample obtained at $360 \mathrm{~W}$, showing the peaks B, D and G.

\subsection{Power influence}

To study the influence of the power input in the CNF synthesis several values of power input were tested and the obtained products were analyzed by SEM technique. Results of these tests are schematized in figure 13 which shows the CNFs evolution in function of power, that higher CNF yields are obtained at $360 \mathrm{~W}$; under this experimental condition the plasma remains very stable. To increase the power capacity several module reactors could 
be assembled into an array. The simplicity of its electric circuitry and adaptability to an AC glow-arc discharge are some of the most attractive features of this method. Modular plasma discharge working in an array has been already reported by Kuo and Koretzky [58, 59].

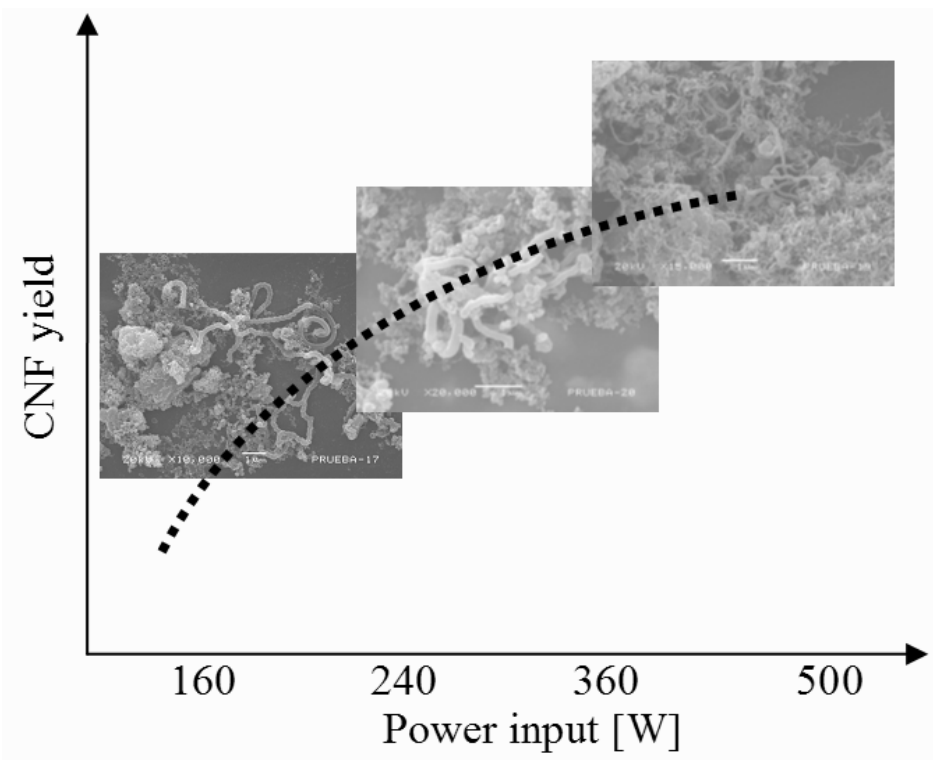

Fig. 13. Qualitatively CNFs yield in function of power input

\subsection{Preliminary results of $\mathrm{NO}_{\mathrm{x}}$ adsorption by CNF}

To determinate the energy of activation in CNF and, then, the process of sorption, CNF samples were contaminated with $\mathrm{NO}_{\mathrm{x}}$. Contaminated and uncontaminated $\mathrm{CNF}$, were analyzed by thermogravimetry (figure 14), that usually consists in weight lost in function of temperature determination.

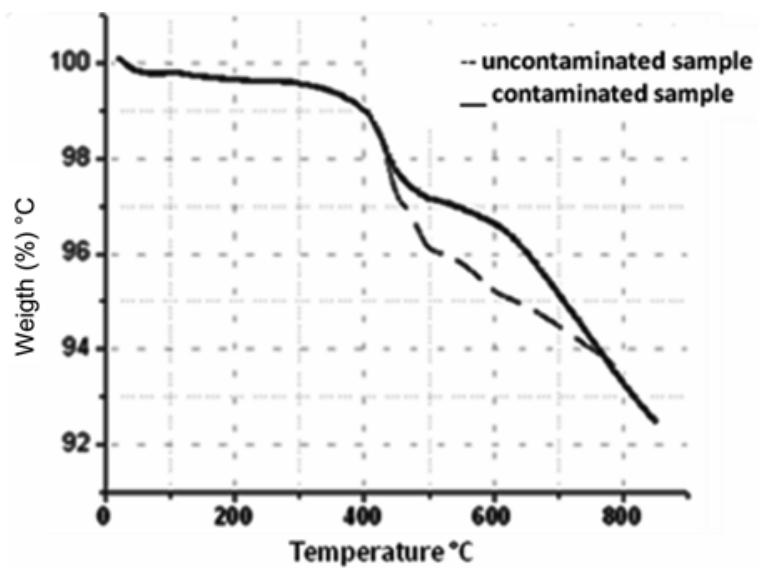

Fig. 14. CNF uncontaminated and contaminated with $\mathrm{NO}_{\mathrm{x}}$ 
By following the next procedure is possible to obtain the energy activation. Equation (1) represents a first order kinetics adsorption

$$
\ln (-\ln (1-\alpha))=\ln \left(\frac{A}{\beta} \frac{R T^{2}}{E_{a}^{\text {des }}}\right)-\frac{E_{a}^{\text {des }}}{R}\left(\frac{1}{T}\right)
$$

Where,

$T$ is temperature

$R=8.134 \mathrm{~J} / \mathrm{mol}-\mathrm{K}$,

A: pre-exponencial factor $\left(\mathrm{s}^{-1}\right)$

$\beta$ : heating velocity $(\mathrm{K} / \mathrm{min})$

$E_{a}^{\text {des }}$ : energy activation

$\alpha$ is the weight loss in function of $T$, more specifically,

$$
\alpha=\frac{m_{o}-m_{T}}{m_{o}-m_{f}}
$$

$m_{o}$ is initial weight at $T, m_{T}$ is the weight in function of $T$ and $m_{f}$ is final weight.

From data of figure 15 , by plotting $\ln (-\ln (1-\alpha))$ versus $1 / T$, is possible to obtain the activation energy of uncontaminated CNF (figure 15a) and from these contaminated with NOx (figure $15 b)$.

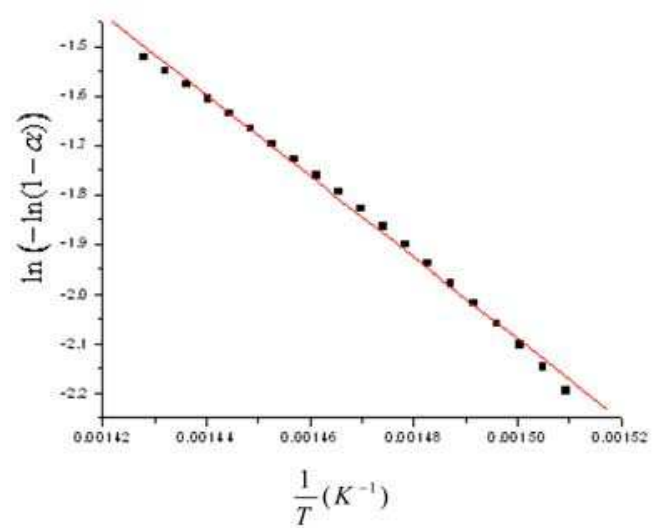

(a)

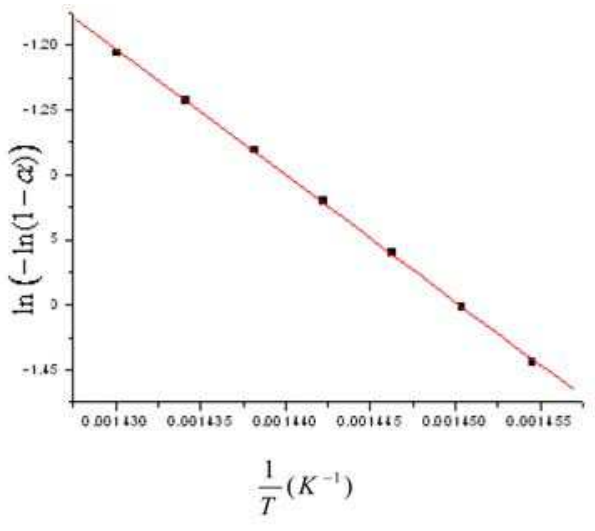

(b)

Fig. 15. (a) Uncontaminated CNF, (b) Contaminated CNF

For the uncontaminated and contaminated samples the values of energy activation respectively are: $E_{a}^{\text {des }}=68.12 \frac{\mathrm{kJ}}{\mathrm{mol}}$ and $E_{a}^{\text {des }}=80.98 \frac{\mathrm{kJ}}{\mathrm{mol}}$. These, relatively low values corresponds to a physical absorption.

These results are similar to values obtained by some others authors (for carbon nanostructures the energy activation is between $10 \mathrm{KJ} / \mathrm{mol}-100 \mathrm{KJ} / \mathrm{mol}[60,61])$. The advantage of the physical adsorption, confirmed by thermogravimetric analysis, is that NOx, could be removed from CNF fluid bed by employing physical means such as a pressure camera. 
An additional experiment was effectuated to test the capacity of adsorption of CNF, consisting in passing a constant flux of 400ppm of NOx during few minutes, through a CNF bed. By employing a NOx sensor (PG250) it was possible to determinate the removal rate being of about $87 \%$. It is worth to note that additional experiments must be done, in order to confirm the life time of the CNF as support in a fluid bed.

\section{Conclusion}

A simple technique for CNFs synthesis is reported, the duration of processes is lower than 5 minutes and it requires neither preheating nor high flux of carrier gas. The synthesis has been achieved by the decomposition of methane in an AC low energy plasma discharge. The formed CNFs, exhibited a diameter of about $80 \mathrm{~nm}$ with relatively no impurities. This purity allows the CNFs to be used as a catalyst support for subsequent applications in polymer composite formation or polluted gas absorbers.

The power input of the plasma discharge is an important parameter in the process, an optimization of the CNF synthesis was obtained at about 360W. A great advantage of using a high frequency electric field consists in controlling the power transferred during the glow discharge, and electric arc modes.

By comparing the energy consumptions for this AC plasma discharge with others different configurations, it is clearly shown that a CNFs synthesis can be produced with minimal energy consumption when this kind of AC glow-arc discharge is used. $800 \mathrm{~kJ}$ are needed to produce $1 \mathrm{~g}$ of CNFs.

Preliminary experimental results shows that CNF obtained have a potential to be used as toxic gas adsorbers.

To increase the power and CNFs production, these modular plasma reactors can be connected in series or parallel configuration. The advantage of using a carbon-containing gas, instead of carbon consumable electrodes, resides in the small amount of energy that is needed to atomize it. All these attributions, would favor the implementation of a novel device for producing research quantities of CNF with a low cost and simplicity.

\section{Acknowledgements}

The supports obtained from the ININ (Mexican Institute of Nuclear Research), CONACyT (the Mexican Council for Technological Education contracts SEP-2004-C01-46959 and PCP), and the ICyTDF (Council for science and technology of México City) are gratefully acknowledged. The authors would also thank M. Durán, M. Hidalgo, F.Ramos, N. Estrada, S. Velazquez, C. Torres, A. Juanico, M.L Jiménez for their assistance in experimental tests and analysis. To M.I. Martínez and J. Pérez del Prado for their valuable help in the microscopy analysis and to L. Escobar-Alarcon for the Raman analysis.

\section{References}

[1] J. M. Blackman, J. W. Patrick, A. Arenillas, W. Shi, and C. E. Snape, "Activation of carbon nanofibres for hydrogen storage" Carbon, vol. 44, no. 8, pp. 1376-1385, Jul. 2006.

[2] P. Serp, M. Corrias, and P. Kalck, "Carbon nanotubes and nanofibers in catalysis", Appl. Catal. A, Gen, vol. 253, no. 2, pp. 337-358, (2003).

[3] C. Park and R. T. K. Baker, "Catalytic behavior of graphite nanofibers supported nickel particles. The effect of chemical blocking on the performance of the system" J. Phys. Chem. B, vol. 103, no. 13, pp. 2453-2459,(1999). 
[4] S.V. Mikhalovsky, , L.I. Mikhalovska, V.G. Nikolaev, V.I Chernyshev, V.V. Sarnatskaya, K.Bardakhivskaya, A.V. Nikolaev, L.A. Sakhno, "Use Of High Surface Nanofibrous Materials In Medicine", Chapter in Nanoengineered Nanofibrous Materials, NATO Science Series, Mathematics, Physics and Chemistry Vol 169, 243-254, (2004)

[5] G. Tejral, N. R. Panyala, J. Havel, "Carbon nanotubes: toxicological impact on human health and environment", J Appl Biomed, 7: 1-13, (2009).

[6] T. Masciangioli and W. X. Zhang, "Environmental technologies at the nanoscale" Environ. Sci. Technol., vol. 37, no. 5, pp. 102-108, (2003).

[7] V. L. Colvin, "The potential environmental impact of engineered nanomaterials" Nat. Biotechnol 21 (10), 1166-1170, (2003).

[8] A.B.M Danna, S.E Iyuke, A. Fakhrul-Razi, T. G. Chuah, M.A.Atieh, M.F Al-Khatib, "Synthesis and Characterization of Carbon Nano-Structures for Methane Storage", Environmental Informatics Archives, Volume 1, 597-605, (2003).

[9] Q.Ngo, S. Krishnan,A.M Cassell, Y. Ominami, J. Li, M. Meyyappan, C.Y.Yang "Electrical Characterization of Carbon Nanofibers for On-chip Interconnect Applications", Proceedings of 2005 5th IEEE Conference on Nanotechnology, Nagoya Japan, July 2005

[10] Q. Ngo, A. M. Cassell, A. J. Austin, J. Li, S. Krishnan, M. Meyyappan, C. Y. Yang, "Characteristics of Aligned Carbon Nanofibers for Interconnect Via Applications", IEEE Electron Device Letters, 27 (4), 221- 224, (2006)

[11] T. Gao and T. H. Wang, "Synthesis and properties of multipod-shaped $\mathrm{ZnO}$ nanorods for gassensor applications" Appl. Phys. A, Solids Surf., vol. 80, no. 7, pp. 1451-1454, (2005).

[12] M. Monthioux, and V. Kuznetsov, "Who should be given the credit for the discovery of carbon nanotubes?", Carbon 44, 1621-1622, (2006)

[13] W.R. Davis, R.J. Slawson, G.R. Rigby, "An unusual form of carbon", Nature 171, 756, (1953).

[14] R. Bacon, "Growth, Structure, and Properties of Graphite Whiskers." J. Appl. Phys, 31(2), 283-290 (1960).

[15] A. Oberlin, M. Endo, and T. Koyama, "Filamentous growth of carbon through benzene decomposition", J. Cryst. Growth, 32, 335 (1976).

[16] M. Endo, T. Koyama, Y. Hishiyama, "Structural Improvement of Carbon Fibers Prepared from Benzene", Jap. J. Appl. Phys., 15, 2073-2076 (1976).

[17] V. Ivanov, J.B. Nagy, P. Lambin, A. Lucas, X.B. Zhang, X.F. Zhang, D. Bernaerts, G. van Tendeloo, S. Amelinckx, J. van Landuyt; "The study of carbon nanotubules produced by catalytic method", Chem. Phys. Lett. 223(4) (1994), 329-335.

[18] N. M. Rodriguez, "A review of catalytically grown carbon nanofibres", J. Mater. Res. 8, 32333250 (1993).

[19] R. T. K. Baker, "Catalytic Growth of Carbon Filaments" Carbon 27(33), 315-323 (1989).

[20] N. M. Rodriguez, A. Chambers, and R. T. K. Baker, "Catalytic Engineering of Carbon Nanostructures", Langmuir 11(1010), 3862-3866 (1995).

[21] C. Park, N. M. Rodriguez, and R. T. K. Baker, "Carbon deposition on Iron-Nickel during interaction with carbon monoxide-hydrogen mixtures", J. Catal. 169 (1), 212-227 (1997).

[22] S.A.Manafi and S. H. Badiee, "Production of carbon nanofibers using a CVD method with lithium fluoride as a supported cobalt catalyst", Research Letters in Materials Science Article ID 850975, 5 pages, (2008)

[23] A.M. Benito, Y. Maniette, E. Munoz, M.T. Martinez, "Carbon nanotubes production by catalytic pyrolysis of benzene", Carbon 36(5), 681-683, (1998).

[24] G.G. Tibbetts, D.W. Gorkiewicz, R.L. Alig; "A new reactor for growing carbon-fibers from liquid-phase and vapor-phase hydrocarbons", Carbon 31(5), 809-814, (1993). 
[25] P. E. Anderson and N. M. Rodriguez, "Influence of the support on the structural characteristics of carbon nanofibers produced from the metal-catalyzed decomposition of ethylene", Chem. Mater. 12, 823-830 (2000)

[26] E.S. Steigerwalt and C. M. Lukehart, "Preparation of graphitic carbon nanofibers with the use of water-soluble supports", J. Nanosci. Nanotech. 2, 25-28, (2002)

[27] D.Sun, L. Wang, D. Wu, and L. Lin, "Electrospun Nanofibers Bundles" Proceedings of the 1st IEEE International Conference on Nano/Micro Engineered and Molecular Systems January 18 - 21, 2006, Zhuhai, China

[28] L. Y. Yeo, J. R. Friend, "Electrospinning carbon nanotube polymer composite nanofibers", Journal of Experimental Nanoscience, Vol. 1, No. 2, June 2006, 177-209.

[29] M. Pacheco « Synthèse des Nanotubes de Carbone par Arc Electrique, PhD Thesis, Université Paul Sabatier, (2003)

[30] E. Dervishi; Z. Li; Y. Xu; V. Saini ; A. R. Biris; D. Lupu; A. S. Biris, "Carbon Nanotubes: Synthesis, Properties, and Applications", Particulate Science and Technology, 27 (2), $107-125$, (2009).

[31] H. Huang, H. Kajiura, Y. Murakami, M.Ata, "Metal sulfide catalyzed growth of carbon nanofibers and nanotubes". Carbon 41, 615-618, (2003).

[32] S. Seraphin, S. Wang, D. Zhou, J.Jiao, "Strings of spherical carbon clusters grown in a catalytic arc discharge", Chem Phys Lett. 228, 506-512, (1994).

[33] H. Kajiura, H. Huang, S. Tsutsui, Y. Murakami, M.Miyakoshi, "High purity fibrous carbon deposit on the anode surface in hydrogen DC arc-discharge", Carbon 40, 2423-2428, (2002)

[34] J. B. O. Caughman, L. R. Baylor, M. A. Guillorn, V. I. Merkulov, D. H. Lowndes, and L. F. Allard, "Growth of vertically aligned carbon nanofibers by low-pressure inductively coupled plasma-enhanced chemical vapor deposition", Appl. Phys. Lett. 83, 1207 (2003);

[35] V. I. Merkulov, A. V. Melechko, M. A. Guillorn, D.H. Lowndes, M. L. Simpson, "Alignment mechanism of carbon nanofibers produced by plasma-enhanced chemicalvapor deposition", Appl. Phys. Lett., 79 (18), 2970-2972 (2001).

[36] H. Le Poche, J. Dijon and T. Goislard de Monsabert, "Radio-frequency plasma system to selectively grow vertical field-aligned carbon nanofibers from a solid carbon source", Carbon , 45 (15), 2904-2916, (2007).

[37] A. Caillard, C. Charles, R.W. Boswell, P. Brault, "Synthesis of Carbon Nanofibers and PtNanocluster-Based Electrochemical Microsystems by Combining Low-Pressure Helicon Plasma Techniques" IEEE Transactions on Plasma Science, 36 (4), 882 - 883, (2008)

[38] R. C. Smith, J. D. Carey, C. H. P. Poa, D. C. Cox, S. R. P. Silva "Electron field emission from room temperature grown carbon nanofibers", J. Appl. Phys. 95, 3153 (2004).

[39] D. Harbec, J. L. Meunier, L. Guo, R. Gauvin, N. El Mallah, "Carbon nanotubes from the dissociation of $\mathrm{C}_{2} \mathrm{Cl}_{4}$ using a DC thermal plasma torch," J. Phys. D, Appl. Phys., 37, 15, pp. 2121-2126, 2004

[40] A. A. Howling, C. Hollenstein, P.-J. Paris, "Direct visual observation of powder dynamics in RF plasma-assisted deposition", Appl. Phys. Lett., 59, no. 12, pp. 1409-1411, 1991.

[41] T. Nitter, T. Aslaksen, F. Melandso, O. Havnes, "Levitation and dynamics of a collection of dust particles in a fully ionized plasma sheath", IEEE Trans. Plasma Sci., vol. 22, no. 2, pp. 159-172, Apr. 1994.

[42] M. Lackowski, A. Jaworek, A. Krupa, "Current-voltage characteristics of alternating electric field charger" , J. Electrost., vol. 58, no. 1/2, pp. 77-89, May 2003.

[43] J. O. Pacheco-Sotelo, R. Valdivia-Barrientos, M. Pacheco-Pacheco, J. F. Ramos-Flores, M. A. Durán-García, J. S. Benitez-Read, "A universal resonant converter for equilibrium and nonequilibrium plasma discharges", IEEE Trans. Plasma Sci., vol. 32, no. 5,pp. 2105-2112, Oct. 2004. 
[44] E. E. Kunhardt, "Generation of large-volume, atmospheric-pressure, nonequilibrium plasmas", IEEE Trans. Plasma Sci., vol. 28, no. 1, pp. 189-200, Feb. 2000.

[45] R. Valdivia-Barrientos, J. Pacheco-Sotelo, M. Pacheco-Pacheco, F. Ramos Flores, A. Cruz-Azocar, M. L. Jiménez López, J. S. Benitez-Read, R. López-Callejas, “Optical and electrical diagnosis of a High-Frequency Glow-Arc Discharge and its Application to the Synthesis of Carbon Nanofibers", IEEE Transaction on Plasma Science, Vol. 35, No. 5, pp 1550-1558, 2007.

[46] M. I. Boulous, P. Fauchais, and E. Pfender, Thermal Plasmas: Fundamentals and Applications, vol. I. New York: Plenum, p. 9. 273, 1994.

[47] M. Pacheco, J. Pacheco, M. Valdivia, L. Bernal, R. Valdivia, A. Huczko, et al., "Synthesis of carbon nanostructures by using thermal plasma torch", Braz.J.Phys., vol. 34, no. 4B, pp. 1684-1688, Dec. 2004.

[48] H. Lange, A. Huczko, M. Sioda, M. Pacheco, M. Razafinimanana, A. Gleizes, "On self absorption method for determination of $C_{2}$ in carbon arc plasma", Progress Plasma Process. Mater., P. Fauchais, Ed. NewYork: Begell House Inc., 2003.

[49] T. Matsuura, K. Taniguichi, and T. Watanabe, "A new type of arc plasma reactor with twelve-phase alternating current discharge for synthesis of carbon nanotubes" 17th Int. Symp. Plasma Chem., Toronto, ON, Canada, Aug. 7-12, 2005, Paper ID 634.

[50] J. Yu, Q. Zhang, J. Ahn, S. F. Yoon, R. Y. J. Li, B. Gan, K. Chew, K. H. Tan, “Synthesis of Carbon nanostructures by microwave plasma chemical vapor deposition and their characterization", Mat. Sci. Eng., vol. B90, no. 1, pp. 16-19, Mar. 2002.

[51] C. T. Hsieh, J.M. Chen, R. R. Kuo, and Y. H. Huang, "Formation and field emission properties of carbon nanofibers by a simplified thermal growth", Rev. Adv. Mater. Sci., vol. 5, no. 5, pp. 459-463, 2003.

[52] E. G. Rakov, S. N. Blinov, I. G. Ivanov, E. V. Rakova, and N. G. Digurov, "Continuos process for obtaining carbon nanofibers", Russ. J. Appl. Chem., vol. 77, no. 2, pp. 187191, Feb. 2004.

[53] X. Zhao, S. Inoue, M. Jinno, T. Suzuki, and Y. Ando, "Macroscopic oriented web of singlewall carbon nanotubes", Chem. Phys. Lett., vol. 373, no. 3/4, pp. 266-271, May 2003.

[54] L. Delzeit, I. McAninch, B. A. Cruden, D. Hash, B. Chen, J. Han "Growth of multiwall carbon nanotubes in an inductively coupled plasma reactor" , J. Appl. Phys., vol. 91, no. 9, pp. 6027-6033, May 2002.

[55] T. Nozaki, Y. Kimura, K. Okazaki, "Carbon nanotubes deposition in glow barrier discharge enhanced catalytic CVD", J. Phys. D, Appl. Phys., vol. 35, no. 21, pp. 1-6, Nov. 2002.

[56] G. S. Choi, Y. S. Cho, S. Y. Hong, J. B. Park, K. H. Son, D. J. Kim, "Carbon nanotubes synthesized by Ni-assisted atmospheric pressure thermal chemical vapor deposition", J. Appl. Phys., vol. 91, no. 6, pp. 3847-3854, Mar. 2002.

[57] C. Pham-Huu, R. Vieira, B. Louis, A. Carvalho, J. Amadou, T. Dintzer, and M. J. Ledoux, "About the octopus-like growth mechanism of carbon nanofibers over graphite supported nickel catalyst", J. Catal., vol. 240, no. 2, pp. 194-202, Jun. 2006.

[58] S. P. Kuo, E. Koretzky, and L. Orlick, "Design and electrical characteristics of a modular plasma torch", IEEE Trans. Plasma Sci., vol. 27, no. 3,pp. 752-758, Jun. 1999.

[59] E. Koretzky and S. P. Kuo, "Characterization of an atmospheric pressure plasma generated by a plasma torch array" Phys. Plasmas, vol. 5, no. 10, pp. 3774-3780, Oct. 1998.

[60] M.A. Keane, "Interfacial Applications in Environmental Engineering", Marcel Dekker, New York., 2003,

[61] C.-H Wu, "Adsorption of reactive dye onto carbon nanotubes: Equilibrium, kinetics and thermodynamics", Journal of Hazardous Materials, 144, 1, 93-100, 2007. 


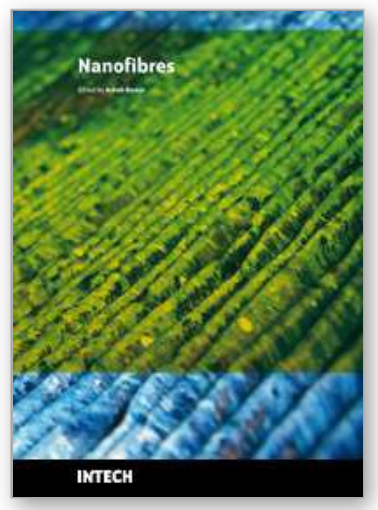

\author{
Nanofibers \\ Edited by Ashok Kumar
}

ISBN 978-953-7619-86-2

Hard cover, 438 pages

Publisher InTech

Published online 01, February, 2010

Published in print edition February, 2010

"There's Plenty of Room at the Bottom" this was the title of the lecture Prof. Richard Feynman delivered at California Institute of Technology on December 29, 1959 at the American Physical Society meeting. He considered the possibility to manipulate matter on an atomic scale. Indeed, the design and controllable synthesis of nanomaterials have attracted much attention because of their distinctive geometries and novel physical and chemical properties. For the last two decades nano-scaled materials in the form of nanofibers, nanoparticles, nanotubes, nanoclays, nanorods, nanodisks, nanoribbons, nanowhiskers etc. have been investigated with increased interest due to their enormous advantages, such as large surface area and active surface sites. Among all nanostructures, nanofibers have attracted tremendous interest in nanotechnology and biomedical engineering owing to the ease of controllable production processes, low pore size and superior mechanical properties for a range of applications in diverse areas such as catalysis, sensors, medicine, pharmacy, drug delivery, tissue engineering, filtration, textile, adhesive, aerospace, capacitors, transistors, battery separators, energy storage, fuel cells, information technology, photonic structures and flat panel displays, just to mention a few. Nanofibers are continuous filaments of generally less than about $1000 \mathrm{~nm}$ diameters. Nanofibers of a variety of cellulose and non-cellulose based materials can be produced by a variety of techniques such as phase separation, self assembly, drawing, melt fibrillation, template synthesis, electrospinning, and solution spinning. They reduce the handling problems mostly associated with the nanoparticles. Nanoparticles can agglomerate and form clusters, whereas nanofibers form a mesh that stays intact even after regeneration. The present book is a result of contributions of experts from international scientific community working in different areas and types of nanofibers. The book thoroughly covers latest topics on different varieties of nanofibers. It provides an up-to-date insightful coverage to the synthesis, characterization, functional properties and potential device applications of nanofibers in specialized areas. We hope that this book will prove to be timely and thought provoking and will serve as a valuable reference for researchers working in different areas of nanofibers. Special thanks goes to the authors for their valuable contributions.

\title{
How to reference
}

In order to correctly reference this scholarly work, feel free to copy and paste the following:

Marquidia Pacheco, Joel Pacheco and Ricardo Valdivia (2010). Synthesis of Carbon Nanofibers by a Glow-Arc Discharge, Nanofibers, Ashok Kumar (Ed.), ISBN: 978-953-7619-86-2, InTech, Available from: http://www.intechopen.com/books/nanofibers/synthesis-of-carbon-nanofibers-by-a-glow-arc-discharge

\section{INTECH}

open science | open minds 


\section{InTech Europe}

University Campus STeP Ri

Slavka Krautzeka 83/A

51000 Rijeka, Croatia

Phone: +385 (51) 770447

Fax: +385 (51) 686166

www.intechopen.com

\section{InTech China}

Unit 405, Office Block, Hotel Equatorial Shanghai No.65, Yan An Road (West), Shanghai, 200040, China

中国上海市延安西路65号上海国际贵都大饭店办公楼 405 单元 Phone: +86-21-62489820

Fax: +86-21-62489821 
(C) 2010 The Author(s). Licensee IntechOpen. This chapter is distributed under the terms of the Creative Commons Attribution-NonCommercialShareAlike-3.0 License, which permits use, distribution and reproduction for non-commercial purposes, provided the original is properly cited and derivative works building on this content are distributed under the same license. 